\title{
Comment
}

\section{Os Desafios no Ensino da História}

\author{
Maria José Lopes de Sousa Morais ${ }^{1}$
}

\begin{abstract}
Resumo: Garantir uma educação de qualidade para todos é um dever do estado. Municipio e União e se adequam conforme as necessidades e a demanda da legislação vigente independente de classe social, cultura, economia, política,localidade e estória.Para que haja uma educação de qualidade é fundamental que na transmissão de conhecimentos haja uma compreensão e uma adequação, que promovam uma reflexão, uma curiosidade,um senso crítico e um interesse de participar por parte do aluno desde o ensino infantil.O professor tem papel essencial nesse processo,já que tem a obrigação de transmitir os conteúdos com clareza e utilizando o cotidiano para uma melhor concretização da aprendizagem,provocando uma reflexão e participação mais efetiva do aluno na escola e na sua localidade.Quando o aluno ingressa no ensino fundamental está com a sua mente em formação, o que permite uma ampliação de suas características pessoais que poderão na sua vida adulta ainda serem observadas,já que a formação da cidadania que deveria ser iniciada pela família, também é transmitida pela escola.Na formação do aluno, a disciplina de história é fundamental pois conhecendo o passado,se entende o presente na busca de um futuro melhor.Isso porque a historia permite a compreensão de ações e gerações em tempos diferentes.A disciplina de história permite a transmissão de fatos que permite o aluno fazer comparações com os dias atuais e seu cotidiano despertando assim curiosidades e interesse de ser parte dela, mesmo que no momento seja só na sua localidade e quem sabe futuramente como parte ampla da história.
\end{abstract}

Palavras chave: Aluno. Ensino. Professor. História.

\section{The Challenges in Teaching History}

\begin{abstract}
Ensure a quality education for all is a duty of the State. County and Union and fit according to the needs and the demand of current legislation regardless of social class, culture, economics, politics, and history. To provide a quality education is fundamental in the transmission of knowledge there is an understanding and an appropriateness, promoting reflection, a curiosity, a critical sense and an interest to participate on the part of the student from the children's education. The teacher's essential role in this process, since it has the obligation to transmit the contents clearly and using the everyday for a better implementation of a learning reflection and more effective participation of the student in school and in your locality. When the student enters the elementary school's with your mind in training, which allows a magnification of personal characteristics which may in his adult lifeainda be observed, since the formation of citizenship which should be initiated by the family, is also transmitted by the school. On student's training, the discipline of history is essential because knowing the past, understand the present one in search of a better future. That's because the story allows the understanding of actions and generations in different times. The discipline of history allows the transmission of facts that allows the student to make comparisons with the present day and your daily life that set off trivia and interest to be part of it, even if at the moment it's just in your locality and who knows in the future as part of history.
\end{abstract}

Keywords: student. Teaching. Professor. Story.

\footnotetext{
${ }^{1}$ Mestrando em Educação pela Unisullivan University. Graduação em Pedagogia pela Universidade Regional do Cariri URCA. E-mail: zezelsmz@gmail.com.
} 


\section{Introdução}

Na formação do cidadão a educação é de essencial importância e durante toda a sua permanência na vida escolar as disciplinas e atividades aplicadas no ensino fundamental é fase inicial desse processo, ajudando no desenvolvimento do aluno tanto fisicamente como psicologicamente.

É nesse momento que o aluno começa a desenvolver suas ideias pessoais e as atividades e disciplinas escolares devem ajuda-lo além de adquirir conhecimentos intelectuais, a buscar compreensão e características pessoais que lhe ajudaram na vida adulta.

A família é de extrema importância na participação da vida escolar do aluno, já que afeta diretamente a formação pessoal através dos exemplos apresentados no cotidiano do mesmo.

A Legislação brasileira buscou regulamentar Leis educacionais com a intenção de oferecer uma educação de qualidade para todos, independente de classe social, cultural,política, econômica, religião ou outras diferenças que possam vir existir. A formação, execução, controle e fiscalização do cumprimento dessas leis são de responsabilidade dos governos Federais, Estaduais e Municipais,envolvendo assim, todos os níveis educacionais ,desde o ensino infantil até o superior.

Através da disciplina de história, podemos conhecer o passado e entender como e porque muitas ações que envolvem o nosso dia a dia foram formadas e desenvolvidas na nossa sociedade e no mundo. É através da história que entendemos como foram formadas as diversas localidades e povos, além das diferentes culturas e sociedades que existem atualmente. Lembrando que a história está sempre em transformação e formação, sendo assim os conhecimentos transmitidos não estão distantes.

O professor da disciplina de história é um mediador do processo de ensino aprendizagem do aluno , pois busca transmitir os conteúdos de maneira clara ,considerando a idade, capacidades e limitações existentes na sua sala, como também levar em consideração fatores externos que possam envolver o repasse e aplicação da disciplina na localidade, tais como, fatores políticos, sociais e econômicos habituais do aluno tornando-o mais atuante e participativo na sua localidade e quem sabe na sociedade geral.

A disciplina de história tem como função pedagógica, aplicar de maneira adequada, características que levem o aluno a desenvolver o interesse do aluno em refletir,formar opinião, ter senso critico, coletivo e participativo, levando-o a querer fazer sua história. 
Assim, o objetivo deste trabalho é demonstrar a necessidade e importância do ensino da disciplina de historia no ensino fundamental para a formação do aluno como um ser consciente e atuante, sendo vital a participação do professor como o mediador e incentivador desse processo.

\section{O Ensino Fundamental e a Disciplina de Historia .}

A Lei de Diretrizes de Bases da Educação LDB(1996) em seu artigo 32º diz que "o objetivo do ensino fundamental no Brasil é a formação básica do cidadão".Sendo assim,podemos dizer que a legislação defende o ensino fundamental e seus objetivos ,para que no Brasil haja condições adequadas para preparar o aluno como um cidadão.

A Lei de Diretrizes e Bases da Educação LDB é responsável pela educação em todas as suas modalidades e níveis, desde o momento que se cria o espaço educacional até as suas adequações e o repasse das informações educacionais.

A história sofre muitas alterações com os progressos tecnológicos, mudanças culturais, políticas e econômicas e como resultado as Leis que conduzem a educação também sofrem alterações para acompanhar suas necessidades na aprendizagem e na preparação dos alunos.

As modificações constantes em nosso mundo que cada vez mais se torna globalizado, exige melhoras na formação e na qualificação de quem precisa atuar e acompanhar as necessidades da sociedade (população).Sendo a educação algo indispensável para que essas modificações ocorram, deve sempre manter-se atualizada, buscando desenvolver a reflexão e o senso crítico e participativo em seus alunos.

Para Ruiz(2008): As políticas educacionais,organizacionais e curriculares são portadoras de intencionalidade, ideias, valores atitudes e devem ser entendidas no quadro mais amplo das transformações políticas, econômicas,geográficas e culturais que caracterizam o mundo.

Vivifica a Constituição que todos têm direito a escola, sendo a mesma fundamental para que o aluno possa desenvolver conhecimentos e características pessoais, a viver em grupos e na sociedade sem grandes conflitos e envolvendo-se com o que ocorre ao seu redor no dia a dia.

A educação infantil e fundamental busca desenvolver fatores que favoreçam a formação intelectual, física e moral do aluno preparando-o para vida como um ser pensante e atuante.

Segundo a LDB, "a educação escolar deve vincular-se ao mundo do trabalho e à prática social."promovendo assim uma educação para que os alunos adquiram conhecimentos com os 
exemplos vivenciados no seu cotidiano.Adquirindo uma melhor aprendizagem com uma melhor qualidade.

Para Maiel(2012): A educação pode significar instrução isto é o resultado de um processo de atividades dirigidas através de interações que é o ensino, e é caracterizado pelo nível de desenvolvimento intelectual. Assim, a educação é a ação de ensinar e conduzir conhecimentos entre alunos e professores e segundo Maiel, a educação tem como característica principal proporcionar ao aluno conhecimento intelectual, transmitindo conteúdos e acatando suas capacidades e limitações, como também sua cultura, sociedade e história.

Através da educação o aluno além de adquirir conhecimentos, está formando características que formaram sua personalidade e comportamento durante toda sua vida.

$\mathrm{Na}$ educação fundamental o desenvolvimento da formação comportamental do aluno ainda é de fácil moldagem entretanto podemos considerar que a formação do mesmo não está completa e que a maneira com que se repassa os conteúdos deve ser clara e de clara compreensão.

No artigo $2^{\circ}$ da LDB:A educação é dever da família e do Estado, inspiradas nos princípios da liberdade e nos ideais de solidariedade humana e tem por finalidade o pleno desenvolvimento do educando.

A escola não deve ser a única a desenvolver na criança características pessoais e até mesmo profissionais, a família também é necessária e importante nessa questão.Só assim o aluno se torna parte integrante do meio em que vive.

Segundo Libanêo (2008) o planejamento da educação no Brasil deve acontecer da seguinte forma:a) elevação global do nível de escolaridade;b)melhoria da qualidade; c)redução das desigualdades;d)democratização da gestão.

Para que o planejamento consiga alcançar seus objetivos é necessário o controle das ações planejadas.Assim, para que isso possa acontecer a educação fundamental deve planejar de acordo com a equiparação dos níveis de ensino, para que a educação possa ser de qualidade e democrática onde todos possam participar.

O aluno através da educação adquire conhecimentos, e através dos mesmos desenvolve curiosidades para aprender mais sobre o seu cotidiano e sobre o mundo que o cerca.

O estudo de historia proporciona ao aluno um conhecimento alem da localidade das regiões e países,pois também transmite informações sobre a cultura,política,economia,ações e mudanças que modifica e adéqua esses lugares como também o mundo. 


\section{A Importancia da Disciplina de Historia no Ensino Fundamental.}

A disciplina de historia é essencial na educação do ensino fundamental. Pereira (2013) diz que: "conhecer sua história permite compreender o que acontece nesse lugar e no mundo e que conhecer os fatos e acontecimentos do passado permite ao aluno entender o porquê dos fatos e características do mundo atual.

O ensino de historia além de transmitir conhecimentos locais e ambientais de onde o aluno vive, também proporciona informações sobre o seu estado, Pais e mundo oportunizando o conhecimento de várias culturas, políticas economias e a diversidade de características existentes que apresenta o ser humano. Conhecer os fatos passados nos permite entender o presente e ajuda na formação e desenvolvimento para o futuro.

A disciplina de historia ensina aos alunos as transformações, mudanças ocorridas com o tempo e como foram desenvolvidas, suas influencias na sociedade e nos tempos atuais. Lembrando que cada lugar tem sua historia e aspectos que influenciam a localidade. As alterações que a sociedade passa são decorrentes de ações sofridas na historia da localidade sejam elas de forma permanente ou não.

Para organizar os tempos históricos, a cronologia é uma ferramenta que proporciona um melhor entendimento dos fatos, porém é uma ferramenta meramente auxiliar.

Todos sem exceções fazemos parte da historia,interferindo no processo da mesma. É claro que algumas pessoas em alguns momentos se destacam por interferirem de maneira mais grandiosa através de ações positivas ou negativas na localidade,em uma esfera de maior grandiosidade ou até mesmo no mundo.

\section{A Prática da Docência em Historia.}

A historia transmite o conhecimento de fatos passados,por isso nem sempre o aluno está interessado em saber sobre o que ocorreu em tempos e lugares longínquos.Nesse caso cabe ao professor conquistar o aluno, desenvolver no mesmo o gosto de aprender sobre os fatos passados que influenciam de maneira direta ou indiretamente o seu dia a dia. 
Pereira (2013): O ensino de historia nas series iniciais devem promover a reflexão e cabe ao professor fazer com que essa reflexão seja efetivada ,ainda que de modo tímido.

É essencial que o professor de historia tenha parceria com a escola e que ambos despertem no aluno o interesse pela disciplina, instigando a curiosidade e o senso critico sobre questões que envolvam o cotidiano para que o mesmo desenvolva uma consciência critica e cidadã, conhecedor que é parte importante da historia.

O método e a prática de como ensinar a disciplina de historia sofreu muitas modificações com o tempo, isto acontece pela participação do aluno e suas diversidades no decorrer das aulas.

As aulas passaram a ter a participação efetiva do aluno e os professores tentam relacionar fatos históricos com o cotidiano dos alunos, deixando claro que todos fazem parte da mesma.

O professor torna-se uma ferramenta na construção do saber do aluno, incentivando para que o mesmo forme suas próprias opiniões e se torne mais participativo nas ações do seu cotidiano e sua localidade.

\section{Considerações Finais}

A disciplina de historia tem essencial papel na formação do aluno pois envolve variados fatores que influenciam o cotidiano e o futuro das nações.

É necessário entender as informações do passado para perceber os fatos atuais e compreender suas influencias locais e mundiais.

No ensino fundamental a criança está em formação e esse momento é ideal para que o intelectual e o caráter sejam formados.Assim há a necessidade do professor transmitir o ensino com exemplos do dia a dia do aluno, para que os mesmos sejam compreendidos com mais facilidade.Nesse momento a família também deve está presente nessa formação e se manterem em parceria com a escola.

Na transmissão dos conteúdos o professor deve relacionar sempre os fatos históricos com o cotidiano do aluno para que o mesmo possa compreender com clareza e facilidade e possa através da curiosidade buscar, participar e desenvolver sua própria historia.

Pode-se concluir que muito mais que só apresentar o passado a disciplina de historia busca despertar no aluno a compreensão do presente e o planejamento para o futuro.Envolvendo sempre todos,para que cada um possa construir sua própria historia. 


\section{Referências}

BERVIAN, P. A.; CERVO, A. L.; SILVA, R. Metodologia Científica. $6^{a}$ ed. São Paulo: Pearson Prentice Hall, 2007.

BRASIL.Lei 9.394/96 Lei de Diretrizes e Bases da Educação- Brasília ,1996;

FLORESCANO. Enrique. A função social do historiador. Tempo (Revista do Departamento de História da UFF) Rio de Janeiro, 1997, vol. 4 . p. 66-68.

LAKOMY, A.M.Teorias Cognitivas da Aprendizagem. 2 ed. Curitiba: Ibex, 2008;

LIBANÊO, J.C. Educação Escolar: políticas,estrutura e organização, São Paulo: Cortez, 2008

MONTEIRO,A.M. Ensino de História:das dificuldades e possibilidades de um fazer. In: DAVIES, N. (Org.) Para além dos conteúdos. Niterói: EDUFF,2001;

PELLEGRINI, M. Vontade de Saber História. Ed. REV:São Paulo, 2009

PEREIRA, J. C.C. O Ensino de Historia nas Serie Iniciais, 2013. Disponível em: <HTTP://www.histedbr.fe.unicamp.br/acer;

SCHIMIDT, M. A.; CAINELLI, M. Ensinar História. São Paulo: Scipione, 2004.

Como citar este artigo (Formato ABNT):

MORAIS, Maria José L. de S. Os Desafios no Ensino da História. Id on Line Revista Multidisciplinar e de Psicologia, Abril de 2017, vol.11, n.35, p.615-621. ISSN: 1981-1179.

Recebido: 25.05 .2017

Aceito: 30.05 .2017 